\title{
Assessing China's Discursive Power: The Concept and Its Effect
}

\author{
Tianyi Bai ${ }^{*}$
}

\author{
${ }^{1}$ School of Zhejiang International Studies \\ *Email: tybai@zisu.com
}

\begin{abstract}
China has attached more attention to gaining discursive power in foreign policy since the early 21 st century with the ever changing international political climate and increasing "China's threat" rhetoric. However, difference between the Chinese and Western definition of the concept has not been stressed. Under such circumstances, the paper aims at assessing the myth surrounding the concept and effect of China's discursive power using the South China Sea issue as a case study. Adopting a cultural-conscious approach-Cultural Approach to Discourse (CAD), the paper analyses China's public diplomacy efforts on obtaining discursive power and safeguarding its rights in the South China Sea. Also international public opinions about the South China Sea issue is explored in order to evaluate the effect of China's discursive power strategy on the SCS issue, with a final aim of engender intercultural dialogue regarding the subject of discursive power and international communication.
\end{abstract}

\section{Keywords: Discursive power, Concept, Effect, the South China Sea Issue}

\section{INTRODUCTION}

Nearly all countries are increasingly seeking discursive power advantages through various means. As a rising power on the international stage, discursive power has already been regarded as China's strategic pillar these days [1]. In 2003, the Chinese government began to revise the guideline of "keeping a low profile" proposed by Deng Xiaoping, as the guidance of national development since 1990s. The new generation of leaders who took power tried to play a more active role in global affairs. China's rise has been the focal point of global attention. China's strategic pillar on discursive power aims at achieving discursive power that is compatible with China's geopolitical power in the international arena, reversing the passive role played by China in the competition for discursive power. It endeavors to actively tackle the western monopoly of discursive power, caused by the dominance of Western countries within international media, so as to achieve cultural exchange and equality [2].

For this purpose, the Chinese government, since the early 2003, has put discursive power on an ever higher place connoting strategic significance. It has gradually formulated a strategy for discursive power which contains setting facts straight, innovating rules, and making breakthroughs in practice. However, the definition of discursive power varies between China and the West, in order to discuss this issue, we have to clarify the concept of discursive power first.

Discursive power not only refers to the power of speaking, but also concerns with the related categories of speaking such as subject, object, content, medium of speaking etc. Within the intricate structure of international arena, discursive power is also indicated by the credibility of what is communicated, moral appeal and national image building ability. So, discursive power is some kind of relational power which derives from the positioning of social factors by specific, usually interactive, discourse practice. Through public diplomacy, international communication and other engagement activities, discursive power is the capability to disseminate national values and ideology, to express position and stance on global affairs and national interest, thus obtaining recognition internationally, guiding and influencing public opinion.

Discursive power consists of three elements: power facts, shared rules among various social groups and social practice. While power facts is the fundamental base of discursive power, shared rules among various social groups are at the core of discursive power, with social practice as the intermediary link between power facts and shared rules. Formation of discourse cannot be 
divorced from social practice, since social practice makes the discourse a reality. Strengthening these three key elements is essential to obtain discursive power on the international stage. Only by uniting shared rules and power facts with social practice, can a country garner greater international discursive power [1].

Discursive power is key indicator of cultural soft power. Transformation of a country's cultural soft power to discourse also needs a "strategic pivot". Through diplomacy, trade, propaganda, international non-governmental exchanges and many other channels, and the integration of all aspects of cross-cultural and cross-border exchanges and the coordination of all resources, cultural soft power advantages could be translated into increased discursive power [3].

There is difference between the Chinese and Western definition of discursive power. The difference of understanding may be caused by different understanding of power, discourse and discursive power, where culture plays an essential role. Culture and national ideology have influence on a nation's discursive power and also influence perception on the concept itself and its components [4].

In Western politics, the term power refers to the ability of one actor or organization to influence the attitude and behavior of another actor of organization. Such a definition is related to the logic of Charles Darwin, focusing on those with power as the subject and those without power as the object. Actually, the definition of power should take into account not only the ability of the power subject, but also the extent of acceptance in the power object. This is the important difference between the ancient Eastern "tribute" system and the modern Western international system. Traditional Chinese thinking about power is that power comes from morality and morality comes from nature [5].

The relational premise in power can also be found in the Chinese understanding of discursive power. Traditional Chinese culture values moral principle as the foundation of politics (wei zheng yi de), which influences China's implementation of discursive power. Chinese people value self-restraint and prefer self-examination and look for self-transformation in attempts to convince or influence others. The art of dealing with differences is key to harmony. In Chinese thinking gaining an audience is not to be equated with attention seeking, which excludes the level of respect the first concept entails. We can voice our opinion, loudly and decisively whenever we wish, but disregarding the interests of the audience can only makes us sound rude, and off-key. This hearer-centerness is in contrast with Western view of power and discourse of power, which is almost exclusively conflictual and adversarial, associated with competition, coercion or domination [6].

\section{METHODOLOGY}

The differences drawn above thus requiring a culturally-inclusive approach to discourse analysis emphasizing that discourse of different communities bear with their unique cultural imprint and differences.

Under the backdrop, we adopt Cultural Approach to Discourse proposed by Professor Shi-xu to conduct the study [7]. CAD is a cultural-conscious paradigm of discourse and communication studies which is designed to enable cross-cultural dialogue and mutual learning. Tracing its intellectual origins from various strands in cultural studies which help discover and dissect contemporary disciplinary practices of cultural domination and discrimination, and the critical work of de-Westernizing communication studies, CAD proceeds from two fundamental, interrelated assumptions. Firstly, the contemporary world order is still deeply unequal and inequitable, with American-Western continued to dominant. Secondly, different human communities communicate differently, with their unique cultural characteristics. Therefore, discourse of different communities bear with their unique cultural imprint and differences.

It is emphatically cultural in nature in the sense that the basic concepts, values and strategies involved in a discursive event or activity may be different across communities of peoples and that such discourses of different communities have unequal power relations between them, as with, say, the Western discourses and the non-Western ones, despite their interconnections and commonality, as well as their internal diversities.

There are, three sets of specific methodology tools within CAD. The first is for data collection, which consists in the stipulation of four kinds of data: (a) background data (for understanding the whole situation of the event/activity under investigation and for knowing how much data will be needed and where to find the data, etc.); (b) first-hand data; (c) secondary data (if and when first-hand data are not sufficient); and, when necessary, (d) complementary data (i.e. indirect data for support, reference, comparison, etc.).

The second set, following from its holistic definition of the object of study, is a shared suite of dialectically interconnected categories for describing, analyzing, explaining, interpreting and evaluating discursive events, namely: Subject, Intent/form/relation, Medium, Purpose/effect, Culture, History. CAD requires the researcher to examine, within the social event, who the participants are (and who are excluded, etc.), what they say, how they say it and what kind of social relation evolves out of the saying, through what mediums (e.g. language, time, space) they communicate, for what purposes, with what effects and consequences, in what historical and intercultural processes and relations. From the point of view of CAD investigations should be 
attentive to all relevant categories of discourse event or activity and their interconnections.

Within the CAD toolkit there is, thirdly, a shared set of global, international and local standards of critique for interpretation and evaluation, which is an essential part of assessment in CAD. The multicultural and international standards include cultural coexistence, equality and prosperity. While local standards must depend on native desires and needs. They are not fixed but subject to continuing dialogue and negotiation. Applying global standards and local ones jointly help discover, characterize the discourse under study and achieve the CAD final objective of cultural dialogue.

In sum, $\mathrm{CAD}$ is a cultural-conscious paradigm of discourse and communication studies that is designed to enable cross-cultural dialogue and mutual learning. Genuine cultural dialogue may be engendered with different communities contributing their unique characteristics without neglecting the inputs from other countries. Adopting CAD as the methodology tool, the next section analyses and assesses China's public diplomacy efforts on obtaining discursive power and safeguarding its rights in the South China Sea. Also international public opinions about the South China Sea issue is explored in order to evaluate the effect of China's discursive power strategy on the SCS issue.

\section{RESULTS}

The escalation of tensions in the South China Sea since 2009 has aroused international attention together with US policy change of pivot to Asia and a rising China safeguarding its territorial claims with more active moves. The SCS disputes is not only competition for territory and maritime resources but also competition of discursive power and international public influence [8].

As a new factor of the South China Sea issue, international media agencies have become the important channel for distributing information on the South China Sea issue. International media's influence on the international public opinions about the South China Sea issue is what China must face when safeguarding its rights in the South China Sea, and is the basis for exploring on how to achieve effective international communication and produce positive international influence in respect of the South China Sea issue. After 2009 , the number of international media reports on the South China Sea issue has increased dramatically. More public diplomacy efforts to communicate Chinese position and clarify Chinese action are vital important in the South China Sea conflicts, as a way to maintain positive country image and safeguard national security in this potential flare-up tension spot that has significant geopolitical importance for China [9].In order to obtain discursive power, China has been actively seeking a more proactive approach, which includes attempt to construct a SCS discourse system, that requires joint efforts from governmental, academic and civil level to mobilize and accumulate a reservoir of resources explaining and illustrating China's legitimacy on its SCS claims and Chinese policy from different perspectives with wider range of mediums and platforms [10]. Instead of passively responding to criticism, China is seeking the ability to influence the salience of topics on the public agenda concerning the SCS issue. It is a slow and gradual process, but this process is demonstrated especially in the SCS arbitration tribunal ruling case, where the integration of discourse from official, quasi-official and civil actors reiterates and justifies China's position on the tribunal ruling, refutes criticisms and clarifies doubts on the "assertive" rhetoric on China's actions on the SCS, the illegitimacy on the jurisdiction and admissibility of the South China Sea Arbitral Tribunal and the Philippines' decision to seek arbitration, exposes inconsistency and ambiguity of the Philippines and the US discourses concerning the SCS issue as well as the US double standard when making judgement concerning China's move and its allies'. Ministry of Foreign Affairs held press conference after releasing of statement and white paper promptly with the media (People's Daily and Guangming Daily) and academia interpreted governmental statement and published commentaries in succession. Non-governmental organization are (The Chinese Initiative on International Law) also highly involved by publishing reports analyzing the international public opinion environment while actively developing track-two diplomacy and establishing dialogue with international publics. Increasing former governmental official and current official (former State Councilor Dai Bingguo, Chairman of the National People's Congress of the People's Republic of China Fu Ying and Foreign Minister Wang Yi etc.) are joining and clarifying Chinese policy on the SCS issue on different international platforms respectively.

Examining international public opinions on South China Sea issue, we found that China is still in a weak position, while Western or American discourse still dominates. China's claims and actions being "aggressive" and concern about potential military confrontation caused by China's actions are still the mainstream public opinion internationally. Especially, in the wake of the Permanent Court of Arbitration's ruling on July 12, 2016, criticisms on China declining to abide by the ruling and inconsistency between Beijing's messaging of friendly relations with their neighbors and peacefully resolve disputes with actions on the ground intensified. China has been targeted as the cause of intensification of SCS disputes and threat to escalation of tensions into military confrontation. China has disseminated messages without being understood and accepted. Cultural and discourse repression and domination by the 
West still exist. The "dangers", "threats" and "untrustworthiness" of China are born, not out of presentations of facts or evidence, but out of particular rhetorical renderings of Western binary thinking and presumptions of "USA-as-guarantor-of-world-peace" and "power-as-hegemony". There is a common implicit assumption that any great power will become hegemonic (regardless of its history and culture); thus, China is a threat to stability because its military is rising or, alternatively, because it is a great power. By emphasizing the power difference between China and the other claimants over the South China Sea, China is portrayed as a serious and growing security hazard in the region of Southeast Asia [11].

\section{CONCLUSION}

From the analysis above, China's discursive power is still in a weak position to influence public opinion. China's continuous effort of accumulating discursive power is still imperative and urgent. Utilizing Chinese cultural resources like dialectic way of thinking and Chinese thousand-year-long Confucian tradition and culture, which holds ren (benevolence), he (harmony), and "never do to others what you would not like them to do to you" as the fundamental principles of being and behaving may help to deconstruct "China's threat" rhetoric, ease misunderstanding and change the dynamic of Western cultural and discourse hegemony by offering new integrative and transformative discourses of mutual respect, cooperation and shared responsibility for world peace and stability.

\section{ACKNOWLEDGMENTS}

The paper is funded by Hangzhou Philosophy and Social Sciences Research Program (M21YD042).

\section{REFERENCES}

[1] Zhao, K. (2016). China's Rise and its Discursive Power Strategy. Chinese Political Science Review, $1,539-564$.

[2] Ge, H. \& Pang, W. (2015). US discourse dominating strategy on the SCS issue (meiguo zai nanhai wenti shang de huayu zhudao zhanlue). Southeast Asia SouthAsian Studies (Dongnanya nanya yanjiu), 3, $18-24$.

[3] Zhang, M. (2012, August 14, 2012). Key indicator on cultural soft power: discursive power (Wenhua ruanshili de zhongyao zhibiao: huayuquan). China Social Science Network. Retrieved from http://www.qstheory.cn/special/2012/dwwh/201208 /t20120814 175699.htm

[4] Wang, X. (2010). Discursive power and Chinese international image building (guoji huayuquan yu zhongguo guoji xingxiang de suzao). Journal of University of International Relations (Guoji Guanxi Xueyuan Xuebao), 6, 58-65.

[5] Wang, W. (2013, October 8, 2013). Grasping Strongly the Leadership, Managerial And Discursive Power Of Ideology (laolao zhanggui yishi xingtai gongzuo lingdaoquan guanliquan huayuquan). People's Daily. Retrieved from http://theory.people.com.cn/n/2013/1008/c40531-2 3117496.html

[6] Karlberg, M. (2005). The power of discourse and the discourse of power: pursuing peace through discourse intervention. International Journal of Peace Studies, 10(1), 1-23.

[7] Shi-xu. (2005). A cultural approach to discourse. New York: Palgrave Macmillan.

[8] Zhao, X. (2015). Sino-US South China Sea conflict from international public opinion perspective (cong guoji yulun shijiao kan zhongmei nanhai zhengduan). World of Public Relations (Gonggong Shijie), 12, 64-67.

[9] Zhou, Q. (2011). Public diplomacy in conflicts through the SCS issue (cong nanhai wenti kan "zhengduan zhong de gonggong waijiao"). International Communication (Duiwai Chuanbo), 9, 24-25.

[10] Xiao A. (2015). Rejuvenating Chinese SCS discursive power (chongzhen zhongguo nanhai wenti huayu xitong). World Knowledge (Shijie Zhishi), 18, 32-35.

[11] Shi-xu. (2015). China's national defense in global security discourse: a cultural-rhetorical approach to military scholarship. Third World Quarterly, 36, 11, 2044-2058. 